Western University

Scholarship@Western

\title{
Neonatal brain: Regional variability of in vivo MR imaging relaxation rates at 3.0 T-initial experience
}

L.A. Williams

lwilliams@lri.sjhc.london.on.ca

N. Gelman

P. A. Picot

D. S. Lee

J.R. Ewing

See next page for additional authors

Follow this and additional works at: https://ir.lib.uwo.ca/anatomypub

Part of the Anatomy Commons, and the Cell and Developmental Biology Commons

Citation of this paper:

Williams, L. A.; Gelman, N.; Picot, P. A.; Lee, D. S.; Ewing, J. R.; Han, V. K.; and Thompson, R. T., "Neonatal brain: Regional variability of in vivo MR imaging relaxation rates at 3.0 T-initial experience" (2005). Anatomy and Cell Biology Publications. 59.

https://ir.lib.uwo.ca/anatomypub/59 
Authors

L. A. Williams, N. Gelman, P. A. Picot, D. S. Lee, J. R. Ewing, V. K. Han, and R. T. Thompson 
Lori-Anne Williams, BESc

Neil Gelman, PhD

Paul A. Picot, PhD

David S. Lee, MB,BS, FRCPC

James R. Ewing, PhD

Victor K. Han, MD, FRCPC, FRCP

R. Terry Thompson, PhD

Published online

10.1148/radiol.2352031769

Radiology 2005; 235:595-603

\section{Abbreviations:}

$\mathrm{GM}=$ gray matter

$\mathrm{ROI}=$ region of interest

$\mathrm{TE}=$ echo time

$\mathrm{TR}=$ repetition time

$\mathrm{WM}=$ white matter

${ }^{1}$ From the Imaging Division, Lawson Health Research Institute, London, Ontario, Canada (L.A.W., N.G., P.A.P., D.S.L., V.K.H., R.T.T.); Department of Medical Biophysics, University of Western Ontario, London, Ontario, Canada (L.A.W., N.G., P.A.P., R.T.T.) Departments of Nuclear Medicine (L.A.W.), Radiology (N.G., R.T.T.), and Maternal and Newborn Health (D.S.L. V.K.H.), St Joseph's Health Care, 268 Grosvenor St, London, ON, Canada N6A 4V2; and Department of Neurology, Henry Ford Health Systems, Detroit, Mich (J.R.E.). Received November 3, 2003; revision requested January 27, 2004; final revision received July 30; accepted September 29. Supported by the Canadian Foundation for Innovation, the Ontario Innovation Trust, the Ontario Research and Development Corporation Fund, and the Canadian Natural Sciences and Engineering Research Council. J.R.E. supported in part by National Institute of Neurological Disorders and Stroke grant 1P01-NS23393. Address correspondence to L.A.W. (e-mail: Iwilliams@Iri.sjhc.london.on.ca).

Authors stated no financial relationship to disclose.

Author contributions:

Guarantor of integrity of entire study, R.T.T.; study concepts and design, all authors; literature research, L.A.W., N.G., R.T.T.; clinical studies, L.A.W. D.S.L., V.K.H.; experimental studies, L.A.W., N.G., P.A.P., R.T.T.; data acquisition, L.A.W., N.G., P.A.P., D.S.L., V.K.H., R.T.T.; data analysis/interpretation, all authors; statistical analysis, L.A.W., N.G., R.T.T.; manuscript preparation, definition of intellectual content, editing, revision/review, and final version approval, all authors

o RSNA, 2005

\section{Neonatal Brain: Regional Variability of in Vivo MR Imaging Relaxation Rates at 3.0 T-Initial Experience ${ }^{1}$}

PURPOSE: To retrospectively investigate regional in vivo magnetic resonance (MR) imaging transverse and longitudinal relaxation rates at $3.0 \mathrm{~T}$ in neonatal brain, the relationship between these rates, and their potential use for gray matter (GM) versus white matter (WM) tissue discrimination.

MATERIALS AND METHODS: Informed parental consent for performance of imaging procedures was obtained in each infant. Informed consent for retrospective image analysis was not required; ethics approval was obtained from institutional review board. At 3.0 T, R1 and R2 were measured in brain regions (frontal WM, posterior WM, periventricular WM, frontal GM, posterior GM, basal ganglia, and thalamus) in 13 infants with suspected neurologic abnormality (two term, 11 preterm). Maps of R1 and R2 were acquired with T1 by multiple readout pulses and segmented spin-echo echo-planar imaging sequences, respectively. Accuracy of R1 and R2 map acquisition methods was tested in phantoms by comparing them with inversion-recovery and spin-echo sequences, respectively. Statistical analysis included linear regression analysis to determine relationship between R1 and R2 and Wilcoxon signed rank test to investigate the potential for discrimination between GM and WM.

RESULTS: In phantoms, R1 values measured with $\mathrm{T} 1$ by multiple readout pulses sequence were $3 \%-8 \%$ lower than those measured with inversion recovery sequence, and R2 values measured with segmented echo-planar sequence were $1 \%-8 \%$ lower than those measured with spin-echo sequence. A strong correlation of $0.944(P<.001)$ between R1 and R2 in neonatal brain was observed. For R2, relative differences between GM and WM were larger than were those for R1 $(z=-2.366, P<.05)$. For frontal $G M$ and frontal $W M,\left(R 2_{G M}-R 2_{W M}\right) / R 2_{W M}$ yielded $0.8 \pm 0.2$ (mean \pm standard deviation) and $\left(\mathrm{R} 1_{\mathrm{GM}}-\mathrm{R} 1_{\mathrm{WM}}\right) / \mathrm{R} 1_{\mathrm{WM}}$ yielded $0.3 \pm 0.09$.

CONCLUSION: Results at 3.0 T indicate that R1 decreases with increasing field strength, while R2 values are similar to those reported at lower field strengths. For neonates, R2 image contrast may be more advantageous than R1 image contrast for differentiation between GM and WM.

o RSNA, 2005

Magnetic resonance (MR) imaging is a powerful technique for noninvasively investigating brain maturation, injury, and abnormalities in neonates. Thus far, the majority of neonatal MR imaging studies have been limited to field strengths of $1.5 \mathrm{~T}$ and lower. The improved signal-to-noise ratio provided at higher field strengths (3.0 T and higher) should be advantageous for imaging and spectroscopy of the neonatal brain. To take advantage of the higher field strengths for neonatal studies, it is necessary to optimize image contrast and to determine which sequences provide the strongest contrast between particular tissues. Optimization of contrast between neonatal brain regions is particularly important for investigating the influence of brain injury or prematurity on the morphologic development of the brain (1-5) because such studies often involve segmentation of brain regions $(6,7)$. 
MR imaging data required for contrast optimization and comparison can be obtained through image-based measurements of the relaxation rates $\mathrm{R} 1$ and $\mathrm{R} 2$ $(\mathrm{R} 1=1 / \mathrm{T} 1, \mathrm{R} 2=1 / \mathrm{T} 2)$. Since relaxation rates, in particular $\mathrm{R} 1$, have been shown to change with changes in field strength (8-12), accurate values for relaxation rates for neonatal brain regions at $3.0 \mathrm{~T}$ must be determined. Although relaxation measurements have been reported at lower field strengths for various preterm and term neonatal brain regions (13-20), no relaxation data have been reported at 3.0 T. In this article, "preterm" and "premature" have been used interchangeably in reference to an infant of less than 37 weeks gestation.

Thus, the purpose of our study was to retrospectively investigate regional in vivo MR imaging transverse and longitudinal relaxation rate values at $3.0 \mathrm{~T}$ in the neonatal brain, the relationship between these values, and their potential use for discrimination between gray matter (GM) and white matter (WM) tissue.

\section{MATERIALS AND METHODS}

\section{MR Imaging System}

Studies were performed with a 3.0-T dual-channel MR imaging-MR spectroscopy system (IMRIS; Innovative Magnetic Resonance Imaging Systems, Winnipeg, Manitoba, Canada) designed for imaging studies in infants. The shortbore magnet (length, $135 \mathrm{~cm}$ ) is equipped with asymmetric gradients with a gradient clear bore of $379 \mathrm{~mm}$ and a maximum gradient strength of 40 $\mathrm{mT} / \mathrm{m}$. Infants were imaged in a $27.4-\mathrm{cm}$ quadrature birdcage coil, which was lined with a layer of barium sulfateloaded vinyl-foam composite soundproofing material (type B-14C; Wilrep, Mississauga, Ontario, Canada). This lining reduced acoustic noise by approximately $15 \mathrm{~dB}$ (A weighted). Sound levels for all sequences used were measured to be less than $85 \mathrm{~dB}$ (A weighted) at the center of the coil. In addition, infants wore molded earplugs (EarClassic; Aearo, Indianapolis, Ind) to provide additional sound attenuation.

\section{R1 Measurements}

MR image-based measurements of R1 were determined with the T1 by multiple readout pulses sequence (21) with a sixsection acquisition, as recently described (11). Six transverse sections, centered at the level of the lateral ventricles, were acquired. Imaging parameters included the following: delay between the final excitation of a given section and the inversion pulse for the next view, 2000 msec; time duration between excitations of the same section, $120 \mathrm{msec}$; echo time (TE), $8 \mathrm{msec}$; section thickness, $3 \mathrm{~mm}$; intersection gap, $1 \mathrm{~mm}$; matrix, $128 \times$ 96; field of view, $160 \mathrm{~mm}$; flip angle, approximately $25^{\circ}$; and total imaging time, approximately 9 minutes 30 seconds. R1 maps were reconstructed according to a recently described automated procedure (11) that does not require prior knowledge of the exact flip angle within each pixel. This is advantageous at higher field strengths, since $B_{1}$ variation within the head increases with field strength. This reconstruction procedure (11) also produced maps of the flip angle for each section with lower resolution $(32 \times 32$ matrix).

\section{R2 Measurements}

Measurements of R2 were determined with a 16-segment spin-echo echo-planar MR imaging sequence. In each infant, images were collected with TE values of $30,60,100,160,200$, and $250 \mathrm{msec}$, except as noted later. The acquisition included eight to 12 transverse sections centered on the lateral ventricles. Six of the sections were matched in position to those for the R1 acquisition. Other imaging parameters included the following: TR - TE, 3400 msec; section thickness, 3 $\mathrm{mm}$; intersection gap, $1 \mathrm{~mm}$; matrix, $128 \times 128$; field of view, $160 \mathrm{~mm}$; imaging bandwidth, $100 \mathrm{kHz}$; and acquisition time, approximately 2 minutes per TE value. Curve fitting for the construction of R2 maps was automated and completed according to an appropriately weighted linear fit of the log of the signal intensity.

To minimize Nyquist ghosting for the segmented echo-planar imaging acquisition, reference image data (ie, data acquired with phase encoding turned off) were acquired and used to perform phase correction $(22,23)$ of k-space echo-planar imaging data after one-dimensional Fourier transform imaging. The TE shifting technique (23) was applied to reduced phase and amplitude discontinuities in k-space-associated T2* decay.

To ensure that the T2 decay curve was not affected by $\mathrm{T} 1$ relaxation, which can be the case if TR is fixed, the quantity TR - TE was held fixed as TE was varied. This minimizing of T1-related effects can be illustrated by considering the amplitude of the spin-echo signal $\left(S_{\mathrm{SE}}\right)$ as a function of TE and TR for a tissue with parameters T1, T2, and $N$ (spin density), as given in an equation in another source (10) and shown here in Equation (1):

$$
\begin{aligned}
S_{\mathrm{SE}}(\mathrm{TE}, \mathrm{TR}) \propto N \cdot & \left(1-2 \cdot e^{-(\mathrm{TR}-\mathrm{TE} / 2) / \mathrm{T} 1}\right. \\
& \left.+e^{-\mathrm{TR} / \mathrm{T} 1}\right) \cdot e^{-\mathrm{TE} / \mathrm{T} 2} .
\end{aligned}
$$

If we define $T_{\mathrm{d}}$ as TR $-\mathrm{TE}$, then Equation (1) becomes

$$
\begin{aligned}
S_{\mathrm{SE}} \propto N \cdot & \left(1-2 \cdot e^{-T_{\mathrm{d}} / \mathrm{T} 1} \cdot e^{-\mathrm{TE} / 2 \mathrm{~T} 1}\right. \\
& \left.+e^{-T_{\mathrm{d}} / \mathrm{T} 1} \cdot e^{-\mathrm{TE} / \mathrm{T} 1}\right) \cdot e^{-\mathrm{TE} / \mathrm{T} 2} .
\end{aligned}
$$

By expanding the exponential factors containing $\mathrm{TE}$, for $\mathrm{TE}<<\mathrm{T} 1$, and retaining only first-order terms, the quantity in parentheses (Eq [2]) becomes equal to 1 $e\left(-T_{\mathrm{d}} / \mathrm{T} 1\right)$. If $T_{\mathrm{d}}$ is held constant, the quantity in parentheses is approximately independent of TE, and, thus, the signal decays exponentially with increasing TE. For the timing parameters used in the present study $\left(T_{\mathrm{d}}=3400 \mathrm{msec}, 30\right.$ msec $\leq \mathrm{TE} \leq 250 \mathrm{msec}$ ) and $\mathrm{T} 1$ of 1000 msec, numeric calculations indicate that the variation of the quantity in parentheses with variation in $\mathrm{TE}$ is extremely small $(<0.05 \%)$. (This represents an overestimate of the variation, since the $\mathrm{T} 1$ of neonatal brain tissue is $>1000 \mathrm{msec}$.)

\section{Phantom Experiments}

To validate the technique, measurements of R1, obtained with the multisection $\mathrm{T} 1$ by multiple readout pulses sequence, were determined with distilled water solution phantoms containing three concentrations of $\mathrm{MnCl}_{2}$ of approximately 0,5 , and $15 \mathrm{mg} / \mathrm{L}$. The concentrations of $\mathrm{MnCl}_{2}$ were chosen to represent a physiologic range of $\mathrm{R} 1$ values for neonatal brain tissue. R1 values were compared with those obtained with a standard single-section inversion-recovery sequence with 16 inversion times ranging from 1 to $10000 \mathrm{msec}$ and a TR of $14000 \mathrm{msec}$ plus inversion time to allow for complete relaxation.

The effect of flip angle variation on measured $\mathrm{R} 1$ values was determined by using a spherical phantom (constructed by L.A.W.) with a diameter of $10 \mathrm{~cm}$ that contained a distilled water solution with $\mathrm{MnCl}_{2}$ concentration of approximately 5 $\mathrm{mg} / \mathrm{L}$. The mean flip angle was measured for two regions of interest (ROIs) that were drawn by one author (L.A.W.) on the flip angle map for each of the six sections. The first ROI corresponded to a circular region drawn in the center of the phantom (radius, approximately 14 $\mathrm{mm})$, and the second corresponded to a ring (thickness, approximately $8 \mathrm{~mm}$ ) drawn near the edge of the phantom. The 
TABLE 1

Characteristics of Infants in This Study

\begin{tabular}{|c|c|c|c|}
\hline Infant & $\begin{array}{l}\text { GA at } \\
\text { Birth } \\
(w k)^{*}\end{array}$ & $\begin{array}{c}\text { Corrected } \\
\text { GA at } \\
\text { Imaging } \\
(w k)^{\dagger}\end{array}$ & Main Diagnosis \\
\hline A & 27 & 28 & Albright hereditary osteodystrophy \\
\hline B & 27 & 32 & Bilateral periventricular leukomalacia \\
\hline C & 30 & 33 & Parenchymal hemorrhage \\
\hline $\mathrm{D}$ & 28 & 33 & Isolated parenchymal cysts \\
\hline $\mathrm{E}$ & 29 & 34 & Bilateral periventricular leukomalacia \\
\hline $\mathrm{F}$ & 29 & 34 & $\begin{array}{l}\text { Grade } 3 \text { intraventricular hemorrhage, hypoxic-ischemic } \\
\text { encephalopathy }\end{array}$ \\
\hline G & 29 & 34 & Bilateral periventricular leukomalacia \\
\hline $\mathrm{H}$ & 35 & 37 & Periventricular leukomalacia, hypoxic-ischemic encephalopathy \\
\hline $\mathrm{i}$ & 26 & 38 & Left-sided periventricular leukomalacia \\
\hline J & 29 & 39 & Grade 2 intraventricular hemorrhage \\
\hline $\mathrm{K}$ & 26 & 40 & $\begin{array}{l}\text { Grades } 2 \text { (right side) and } 4 \text { (left side) intraventricular } \\
\text { hemorrhage }\end{array}$ \\
\hline $\mathrm{L}$ & 41 & 42 & Hypotonia \\
\hline $\mathrm{M}$ & 42 & 43 & Hypoxic-ischemic encephalopathy \\
\hline
\end{tabular}

Note.-GA = gestational age.

* Gestational age is the number of completed weeks of gestation according to maternal menstrual dates at birth.

$\dagger$ Corrected gestational age is the gestational age at birth plus the postnatal age.

same ROIs were placed on the R1 maps in areas that corresponded to the ROIs drawn on the flip angle maps, and the mean R1 was measured for each of the two regions.

Measurements of R2, determined with the segmented spin-echo echo-planar imaging sequence, were performed by using distilled water solution phantoms $\left(\mathrm{MnCl}_{2}\right.$ concentration, approximately 4 , 6,8 , and $20 \mathrm{mg} / \mathrm{L}$ ). The concentrations of $\mathrm{MnCl}_{2}$ were chosen to represent a physiologic range of $\mathrm{R} 2$ values for neonatal brain tissue. R2 values were compared with those obtained with a standard single-section single-echo spin-echo sequence with the same phantoms and $\mathrm{TE}$ values of $30,60,100,160,200$, and 250 msec and TR - TE of $10000 \mathrm{msec}$.

\section{Neonatal Subjects and Protocol}

Infants who were admitted to the Neonatal Intensive Care Unit at St Joseph's Health Care, London, Ontario, Canada, between January 1, 2001, and January 1, 2003, and who underwent 3.0-T MR imaging during their hospitalization because they were suspected of having neurologic abnormalities were included in this study. Informed parental consent to perform the imaging procedures was obtained in each infant. Ethics approval was obtained from the institutional review board for our study. Informed consent for retrospective image analysis was not required by the institutional review board. The cohort included 13 consecu- tive patients (Table 1), eight male and five female infants. The gestational age, as the number of completed weeks of gestation according to maternal menstrual dates at birth, varied from 26 weeks to 42 weeks (median, 29 weeks). Depending on infant stability and the urgency of the clinical imaging, corrected gestational age (gestational age at birth plus postnatal age) at imaging varied from 28 weeks to 43 weeks (median, 34 weeks).

Infants were sedated for 3.0-T MR imaging with an oral dose of $25-50 \mathrm{mg} / \mathrm{kg}$ chloral hydrate (Chloral Hydrate 500 $\mathrm{mg} / 5 \mathrm{~mL}$; Pharmascience, Montreal, Quebec, Canada) prior to arrival at the 3.0-T MR imaging suite. Infants were swaddled and laid on their sides with gentle head restraint in an attempt to maximize infant comfort and minimize infant motion. Infant heart rate and oxygen saturation levels were continuously monitored during imaging. In addition, an infrared video monitoring system was interfaced to the system to allow a view of the infant's head and provide a means to watch for motion. Image-based measurements of R1 and R2 were determined with the methods described previously.

Data to reconstruct R1 maps for infants A, G, J, and $\mathrm{K}$ and R2 maps for infant D were not acquired because of the limited time during which each infant remained still. In addition, images for infants $\mathrm{E}$ $(\mathrm{TE}=100 \mathrm{msec}), \mathrm{G}(\mathrm{TE}=60$ and 200 $\mathrm{msec}), \mathrm{J}(\mathrm{TE}=200$ and $250 \mathrm{msec})$, and $\mathrm{K}$ $(\mathrm{TE}=60$ and $200 \mathrm{msec}$ ) were not ac- quired for the same reason. Images were analyzed for motion artifacts by one author (L.A.W.) in consultation with another author (N.G.) and were discarded if artifact-to-signal ratio was greater than $15 \%$ (artifact-to-signal ratio $=\left[S I_{\mathrm{G}}-\right.$ $\left.S I_{\mathrm{N}}\right] / S I_{\mathrm{WM}}$, where $S I_{\mathrm{G}}=$ signal intensity of image ghost, $S I_{\mathrm{N}}=$ signal intensity of image noise, $S I_{\mathrm{WM}}=$ signal intensity from region of $W M$ ). With these criteria, the R1 data set and images for infant $\mathrm{E}$ ( $\mathrm{TE}=60$ and $160 \mathrm{msec}$ ) were discarded. R2 maps were reconstructed by using the remaining images for infants $\mathrm{E}(\mathrm{TE}=30$, 200 , and $250 \mathrm{msec}), \mathrm{G}$ and $\mathrm{K}(\mathrm{TE}=30$, 100,160 , and $250 \mathrm{msec}$ ), and $\mathrm{J}(\mathrm{TE}=30$, 60,100 , and $160 \mathrm{msec}$ ).

\section{Image Analysis}

Mean values for relaxation rates were measured from ROIs within frontal WM, posterior WM, periventricular WM, frontal GM, posterior GM, basal ganglia, and thalamus. ROIs for the basal ganglia and thalamus were located on a single section, whereas ROIs for the frontal WM, posterior $\mathrm{WM}$, periventricular $\mathrm{WM}$, frontal GM, and posterior GM were obtained from a single section at the level of the centrum semiovale. Measurements for frontal WM, posterior WM, periventricular WM, basal ganglia, and thalamus were determined by using one ROI that encompassed tissue from the region. To avoid contamination of the GM regions with the surrounding $\mathrm{WM}$, measurements for frontal GM and posterior GM were determined by selecting several individual pixels within clearly defined GM regions.

The size of the ROI was dependent on the brain region and ranged as follows: in frontal WM, 33-77 $\mathrm{mm}^{2}$ (mean, 56 $\mathrm{mm}^{2}$ ); in posterior $\mathrm{WM}, 42-88 \mathrm{~mm}^{2}$ (mean, $63 \mathrm{~mm}^{2}$ ); in periventricular $\mathrm{WM}$, 16-23 $\mathrm{mm}^{2}$ (mean, $20 \mathrm{~mm}^{2}$ ); in frontal GM, 23-39 $\mathrm{mm}^{2}$ (mean, $28 \mathrm{~mm}^{2}$ ); in posterior GM, 17-34 $\mathrm{mm}^{2}$ (mean, $26 \mathrm{~mm}^{2}$ ); in basal ganglia, $53-145 \mathrm{~mm}^{2}$ (mean, 106 $\mathrm{mm}^{2}$ ); and in thalamus, $31-75 \mathrm{~mm}^{2}$ (mean, $61 \mathrm{~mm}^{2}$ ). Measurements were obtained from both the left and the right hemispheres of the brain for each ROI and then were averaged to yield a value for each region of the brain. Because of section positioning in infant I, all measurements were determined at the level of the basal ganglia, and measurements for basal ganglia and thalamus were from only the right hemisphere of the brain. ROIs for R1 measurements were drawn on R1 maps, and those for R2 measurements were drawn on R2 maps. To main- 
tain consistency, all ROIs were drawn by one author (L.A.W., with 4 years of experience in neonatal brain MR imaging) in consultation with a neuroradiologist with 14 years of experience in neonatal brain imaging.

In each infant, the flip angle variation over the two sections used for R1 measurement was assessed by measuring the mean flip angle for two ROIs that were drawn by one author (L.A.W.) on the flip angle maps. The first ROI was drawn as a circular region (radius, approximately 10 $\mathrm{mm}$ ) in the center of the brain, and the second ROI was drawn as a ring (thickness, approximately $8 \mathrm{~mm}$ ) near the edge of the brain.

All image analysis was performed by using a software package (Eigentool; Image Analysis Laboratory, Department of Diagnostic Radiology, Henry Ford Hospital and Health Sciences Center, Detroit, Mich).

\section{Statistical Analysis}

To ascertain whether there were differences between relaxation measurements in the left and the right hemispheres for each ROI, a separate within-subject analysis of variance was conducted for the hemisphere and the ROI for both R1 and R2.

The relationship between R1 and R2 values in the neonatal brain was investigated by applying a linear regression analysis to the data points from all ROIs where acquisition of both R1 and R2 data was successful. In addition, R1 and R2 values were averaged for each ROI, and the Pearson product moment correlation coefficient and Spearman rank correlation coefficient $(\rho)$ were calculated.

For the purpose of determining which relaxation rate (R1 or $\mathrm{R} 2$ ) is better for discrimination between WM and GM in the neonatal brain, the relative differences were calculated with $\left(\mathrm{R} 1_{\mathrm{FGM}}-\right.$ $\left.\mathrm{R} 1_{\mathrm{FWM}}\right) / \mathrm{R} 1_{\mathrm{FWM}}$ and $\left(\mathrm{R} 2_{\mathrm{FGM}}-\mathrm{R} 2_{\mathrm{FWM}}\right) /$ $\mathrm{R} 2{ }_{\mathrm{FWM}}$ in each infant in whom both R1 and $\mathrm{R} 2$ data were available. $\mathrm{R} 1_{\mathrm{FGM}}$ and $\mathrm{R} 1_{\mathrm{FWM}}$ represent the $\mathrm{R} 1$ values for frontal GM and frontal WM, respectively, and $\mathrm{R} 2_{\mathrm{FGM}}$ and $\mathrm{R} 2_{\mathrm{FWM}}$ represent the $\mathrm{R} 2$ values for frontal GM and frontal WM, respectively. Relative differences for both R1 and R2 were compared with the Wilcoxon signed rank test.

All statistical analyses were performed with a software package (SPSS, version 10.0.7; SPSS, Chicago, Ill). Results that showed a difference with $P<.05$ were considered statistically significant.

\section{TABLE 2 \\ Phantom R1 Values Obtained with Multisection T1 and Single-Section Inversion- Recovery MR Imaging Sequences}

\begin{tabular}{ccc}
\hline \multirow{2}{*}{$\begin{array}{c}\text { Phantom } \mathrm{MnCl}_{2} \\
\text { Concentration }(\mathrm{mg} / \mathrm{L})\end{array}$} & \multicolumn{2}{c}{ R1 Value $^{*}$} \\
\cline { 2 - 3 } & $\mathrm{T} 1$ Sequence & Inversion-Recovery Sequence \\
\hline 5 & $0.33 \pm 0.008$ & $0.36 \pm 0.002$ \\
15 & $0.58 \pm 0.009$ & $0.61 \pm 0.005$ \\
& $1.04 \pm 0.013$ & $1.07 \pm 0.005$ \\
\hline
\end{tabular}

Note.-T1 sequence refers to $\mathrm{T} 1$ by multiple readout pulses MR imaging sequence.

* Values are expressed as the mean seconds \pm standard deviation.

\section{TABLE 3 \\ Phantom R2 Values Obtained with Multisection Segmented Echo-Planar and Single-Section Single-Echo Spin-Echo MR Imaging Sequences}

\begin{tabular}{ccc}
\hline \multirow{2}{*}{$\begin{array}{c}\text { Phantom } \mathrm{MnCl}_{2} \\
\text { Concentration }(\mathrm{mg} / \mathrm{L})\end{array}$} & R2 Value* \\
\cline { 2 - 3 } & Echo-Planar Sequence & Spin-Echo Sequence \\
\hline 4 & $3.08 \pm 0.17$ & $3.34 \pm 0.08$ \\
8 & $4.44 \pm 0.14$ & $4.75 \pm 0.08$ \\
20 & $5.82 \pm 0.19$ & $5.87 \pm 0.12$ \\
& $12.15 \pm 0.45$ & $12.37 \pm 0.25$ \\
\hline * Values are expressed as the mean seconds \pm standard deviation. \\
\hline
\end{tabular}

\section{RESULTS}

\section{Phantom Experiments}

Table 2 provides a comparison between the R1 values measured with the phantoms by using the T1 by multiple readout pulses sequence and those measured by using the inversion-recovery sequence. Values of R1 obtained by using the $\mathrm{T} 1$ by multiple readout pulses sequence are approximately $0.03 \mathrm{sec}^{-1}$ lower than those obtained by using the inversion-recovery sequence. This difference corresponds to an approximate relative difference of 3\% for phantoms with a high $\mathrm{R} 1$ and up to $8 \%$ for phantoms with a low R1.

The relative difference in $\mathrm{R} 1$ between the two regions in the spherical phantom was reasonably small (mean, $3.3 \% \pm 0.3$ [standard deviation]) compared with the relative flip angle difference $(8.9 \% \pm 0.7$ [standard deviation]).

Table 3 provides a comparison between the R2 values measured by using the segmented echo-planar imaging sequence and those measured by using the standard spin-echo sequence. R2 values obtained with segmented echo-planar imaging were $1 \%-8 \%$ lower than the values obtained with the spin-echo method.

\section{Neonatal Subjects}

Representative R1 and R2 maps are shown in Figure 1 for infant J. The sec- tions on the left were obtained at the level of the centrum semiovale where the frontal WM, periventricular WM, posterior WM, frontal GM, and posterior GM can easily be identified. The sections on the right were obtained at the level of the basal ganglia where the basal ganglia and thalamus can be identified. Statistical analysis showed that, for both R1 and R2, there were no significant interactions between the measurements for the left and the right hemispheres and the ROI or main effects for the hemisphere or the ROI. The regional variability of R1 and R2 are shown in Figures 2 and 3, respectively.

In the neonatal brain, the difference in flip angle (mean, $7.7 \% \pm 1.5$ [standard deviation]) between the two ROIs used for flip angle assessment was similar to that obtained with the phantom (mean, $8.9 \% \pm 0.7$ [standard deviation]).

There was a strong correlation $(r=$ 0.944, $P<.001$ ) between measured R1 and R2 values in the neonatal brain (Fig 4). The linear regression analysis was applied to the data points from all ROIs for infants $\mathrm{B}, \mathrm{C}, \mathrm{F}, \mathrm{H}, \mathrm{I}, \mathrm{L}$, and $\mathrm{M}$. The mean regression parameters, slope and intercept, were found to be $0.036 \mathrm{sec}^{-1} \pm$ 0.002 (standard error) and $0.215 \mathrm{sec}^{-1} \pm$ 0.011 (standard error), respectively. In addition, after averaging across subjects for a given region, a significant difference was observed in both the Pearson prod- 


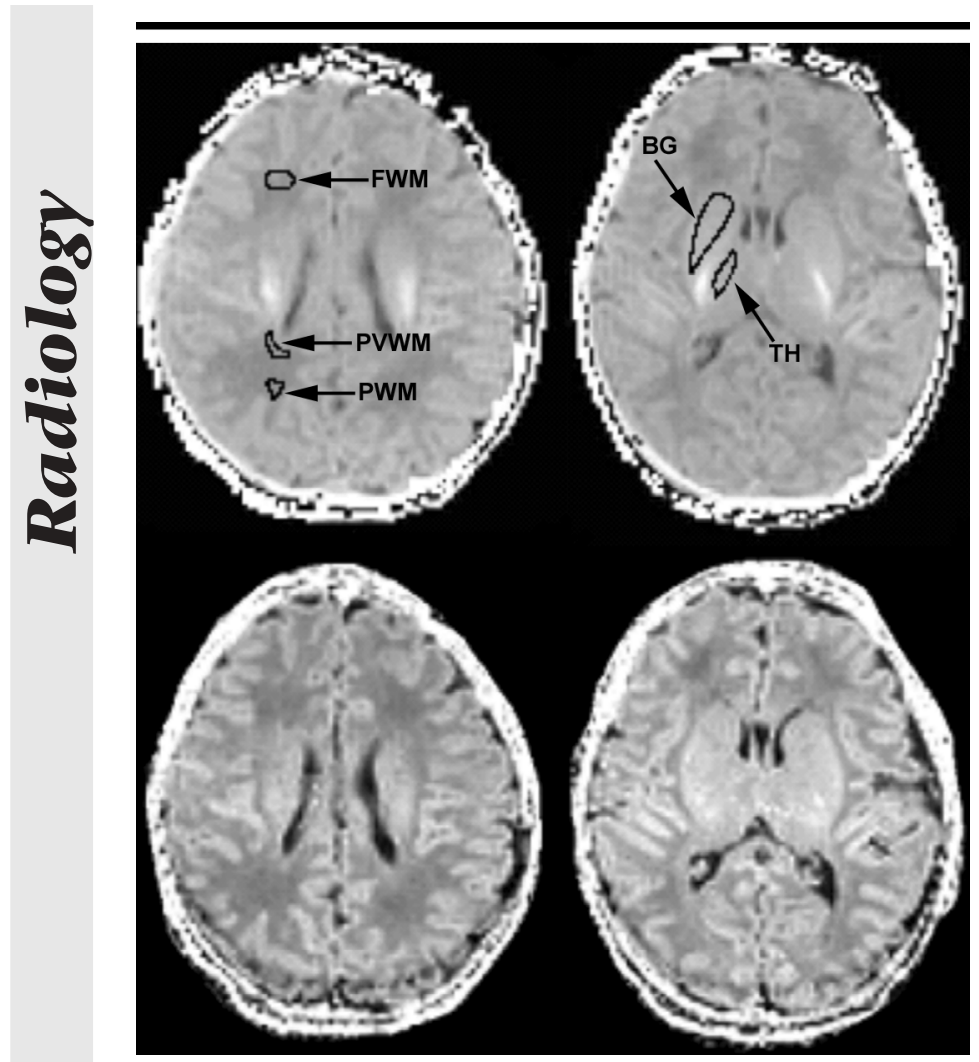

Figure 1. Transverse R1 maps (top row) and R2 maps (bottom row) in infant $\mathrm{J}$ (Table 1) illustrate positions of ROIs used for quantitative analysis. Frontal WM $(F W M)$, posterior WM $(P W M)$, periventricular WM $(P V W M)$, frontal GM, and posterior GM can be identified on the section obtained at level of centrum semiovale shown at left. Basal ganglia $(B G)$ and thalamus $(T H)$ can be identified on the section obtained at level of basal ganglia shown at right. Areas outlined in black demarcate representative ROIs in each region. Frontal GM and posterior GM regions were determined as described in the text. Imaging parameters included section thickness, $3 \mathrm{~mm}$; section gap, 1 $\mathrm{mm}$; and acquired matrix size, $128 \times 96$ for R1 maps and $128 \times 128$ for R2 maps.

uct moment correlation coefficient, which was $0.997(P<.001)$, and the Spearman $\rho$, which was $0.891(P<.01)$.

The mean relative $\mathrm{R} 2$ difference between $\mathrm{GM}$ and WM $(0.8 \pm 0.2$ [standard deviation]) was significantly greater than the mean relative $\mathrm{R} 1$ difference $(0.3 \pm$ 0.09 [standard deviation]), on the basis of the Wilcoxon signed rank test $(z=$ $-2.366, P<.05)$. In fact, the relative R2 difference was greater than that of R1 in all compared cases.

\section{DISCUSSION}

Relationship between R1 and R2 in Neonatal Brain Tissue

Our results indicate a strong correlation $(r=0.944)$ between the values of R1 and $\mathrm{R} 2$ in brain regions in this group of neonates examined at 3.0 T. This suggests that the interregional variation of $\mathrm{R} 1$ and

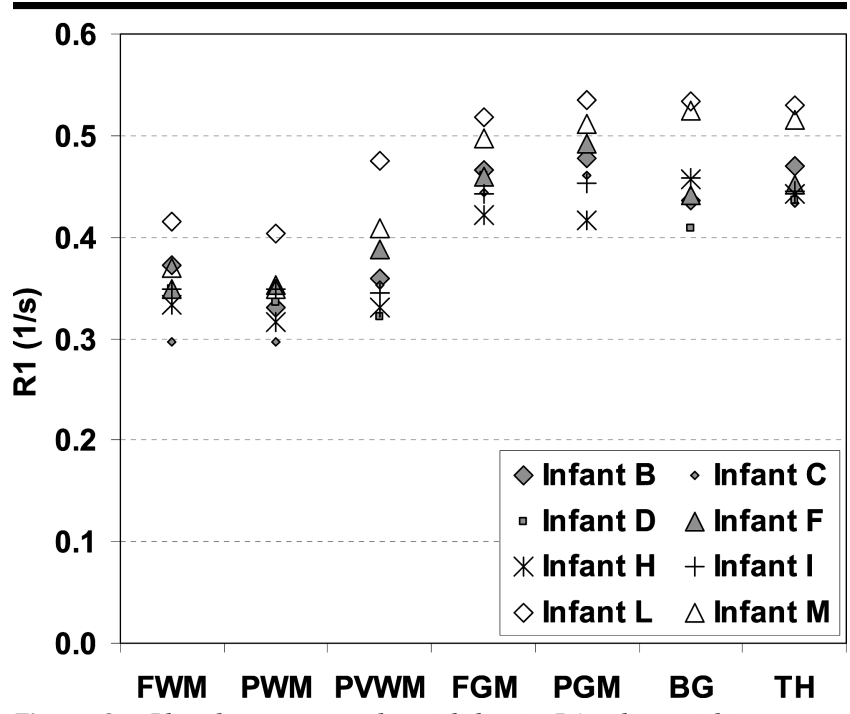

Figure 2. Plot shows regional variability in R1 values within neonatal brain regions, which include frontal WM ( $F W M)$, posterior WM $(P W M)$, periventricular WM $(P V W M)$, frontal GM (FGM), posterior GM $(P G M)$, basal ganglia $(B G)$, and thalamus $(T H)$. Values plotted are the mean values of the left and right hemispheres, except those of infant $\mathrm{H}$ (see Materials and Methods for details). Infants B, C, D, and $\mathrm{F}$ were premature infants imaged at a premature age; infants $\mathrm{H}$ and $\mathrm{I}$, premature infants imaged at a term age; and infants $\mathrm{L}$ and $\mathrm{M}$, term infants imaged at a term age.

served in age-related changes in $\mathrm{R} 1$ and $\mathrm{R} 2$ in an animal model (27).

Findings in previous studies about relaxation rates indicate that, in healthy adults, the interregional variation in values for R1 appears to be related largely to water content $(11,26)$, whereas that in values for R2 is also strongly influenced by levels of tissue iron stores (28-31). (In adults, at $3.0 \mathrm{~T}$, regional values of $\mathrm{R} 2$ are greatest in the iron-rich deep GM region [28], whereas R1 is greatest in the WM region [11], which is the region with lowest water content.) We do not expect tissue iron stores, however, to strongly influence R2 values in neonates because of the extremely low iron levels in such subjects at this age $(32,33)$. flect variations in water content. Investigators in previous reports demonstrated a linear correlation between R1 and water content in vitro $(24,25)$ and in vivo $(11,24-26)$ and an almost linear relationship between R2 and water content (at low water content) in vitro (25). In human neonates, tissue water would be expected to decrease with increasing age and vary with region, according to the level of maturational changes, such as myelination, since maturation is typically accompanied by increases in the content of tissue "semisolids" (ie, major components of the tissue other than water). This relationship between R1 and R2 is consistent with what has been ob-

\section{Estimates of Brain Tissue Water Content in Neonates}

In previous in vivo studies in the adult brain, regression analysis provided a linear relationship between the interregional variation of $\mathrm{R} 1$ in healthy adults and estimates of regional water content $(11,26)$. If we assume that the relationship between R1 and tissue water content in the neonatal brain is similar to the relationship previously reported in the adult brain, then a rough estimate of the water content of neonatal WM and GM can be obtained. When we substitute our 


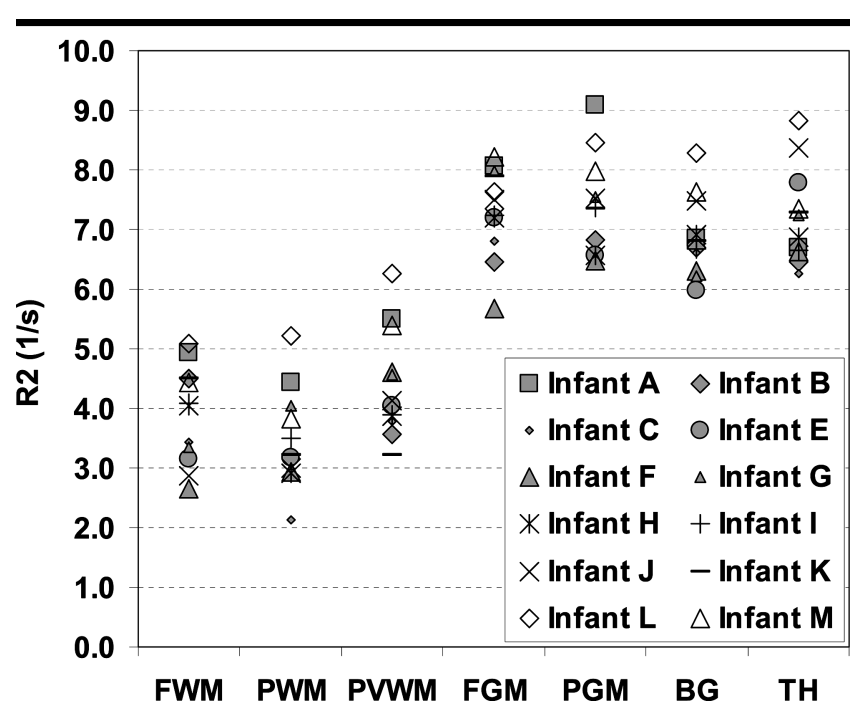

Figure 3. Plot shows regional variability in R2 values within neonatal brain regions, which include frontal WM $(F W M)$, posterior WM $(P W M)$, periventricular WM (PVWM), frontal GM (FGM), posterior GM (PGM), basal ganglia $(B G)$, and thalamus $(T H)$. Values plotted are mean values of the left and right hemispheres, except those of infant H (see Materials and Methods for details). Infants A, B, C, E, F, and G were premature infants imaged at a premature age; infants $\mathrm{H}, \mathrm{I}, \mathrm{J}$, and $\mathrm{K}$, premature infants imaged at a term age; and infants $\mathrm{L}$ and $\mathrm{M}$, term infants imaged at a term age.

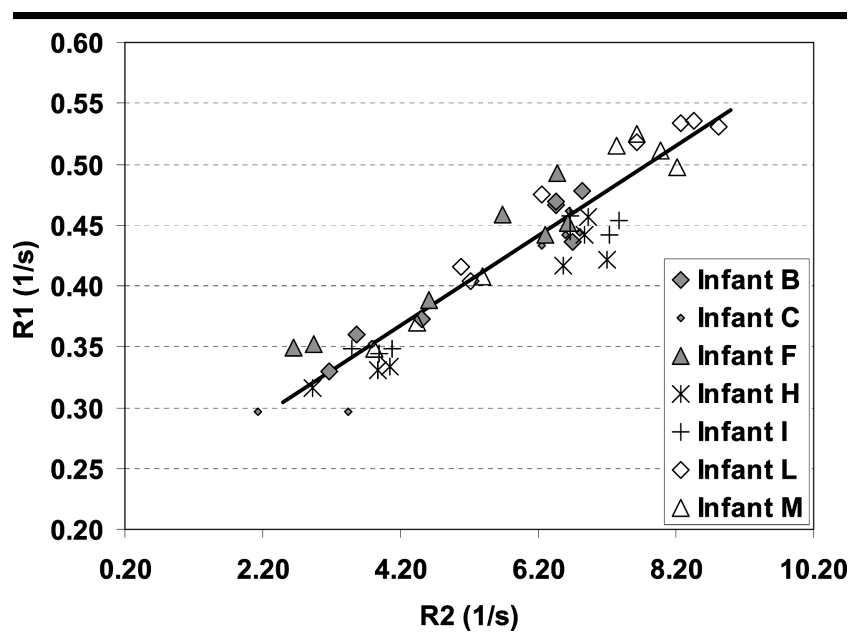

Figure 4. Graph shows correlation of R1 and R2 relaxation rates measured in several brain regions. Plot includes only data from which both R1 and R2 measurements were successful (see Materials and Methods for details). Values plotted are the mean values of the left and right hemispheres, except those of infant $\mathrm{H}$ (see Materials and Methods for details). Infants B, C, and $\mathrm{F}$ were premature infants imaged at a premature age; infants $\mathrm{H}$ and I, premature infants imaged at a term age; and infants $\mathrm{L}$ and $\mathrm{M}$, term infants imaged at a term age. Observed correlation between R1 and R2 suggests that, for neonatal brain tissue, interregional variation of these two relaxation rates may largely reflect variations in the same tissue property, perhaps water content. average $\mathrm{R} 1$ values in the term neonatal brain in the equation for the previously reported linear relationship $(\mathrm{R} 1=$ $1.99 \cdot\left[1 / f_{\mathrm{w}}\right]-1.75$, where $f_{\mathrm{w}}=$ water content $=m_{\mathrm{w}} / m_{\mathrm{tt}}$ [where $m_{\mathrm{w}}$ is water mass and $m_{\mathrm{tt}}$ is total tissue mass]) and solve for $f_{\mathrm{w}}$, we estimate the water content of frontal WM and frontal GM in term neonates to be $93 \%$ and $88 \%$, respectively.

Similarly, for the premature infant brain, we can estimate that the frontal WM water content is approximately $94 \%$ and the frontal GM water content is approximately $90 \%$. Although the relationship between R1 and water content was obtained from studies in adults, our predictions are reasonable, given the results of a postmortem study in which the researchers found that the whole-brain water content at birth was $88 \%$. Researchers in that study also found that whole-brain water content decreased to $82 \%$ by 6 months of age (34). Also, it is well known that the water content of WM is greater than that of GM during the neonatal period (5). This finding is in contrast to findings in the adult brain, where the tissue water content of frontal GM is greater than that of frontal WM, each of which was reported to be $80 \%-86 \%$ and $70 \%$, respectively $(11,26,35-37)$. The large decrease in the WM water content as the brain develops into adulthood is explained by prominent maturational changes, such as myelination. This decrease in water content is associated with increased values of R1 and R2.

\section{Implications for Contrast Optimization at MR Imaging in Neonates}

For the neonatal brain, our results indicate that $\mathrm{R} 2$ values have better potential than do R1 values for discrimination between GM and WM. In adults, R1based discrimination is typically stronger. This is demonstrated in Figure 5 , which illustrates a comparison of values in our study for relaxation rates in neonatal frontal WM and frontal GM with adult values of R1 (Fig 5a), which were measured previously (11) by using the T1 by multiple readout pulses sequence, and with values of R2 (Fig 5b), which were measured previously (28) by using the gradient-echo sampling of free induction decay and echo sequence (38). Figure 5 demonstrates that, for neonates, the relative difference in $\mathrm{R} 2$ values between $\mathrm{WM}$ and GM ([R2 $\left.2_{\mathrm{FGM}}-\mathrm{R} 2_{\mathrm{FWM}}\right] /$ $\left.\mathrm{R} 2_{\mathrm{FWM}}=0.8\right)$ is stronger than that associated with $\mathrm{R} 1$ values $\left(\left[\mathrm{R} 1_{\mathrm{FGM}}-\mathrm{R} 1_{\mathrm{FWM}}\right]\right.$ / $\left.\mathrm{R} 1_{\mathrm{FWM}}=0.3\right)$. In adults, however, the relative difference in $\mathrm{R} 1$ between $\mathrm{WM}$ and $\mathrm{GM}\left(\left[\mathrm{R} 1_{\mathrm{FWM}}-\mathrm{R} 1_{\mathrm{FGM}}\right] / \mathrm{R} 1_{\mathrm{FGM}}=1.1\right.$ [Fig 5a]) is stronger than is the difference in $\mathrm{R} 2\left(\left[\mathrm{R} 2_{\mathrm{FWM}}-\mathrm{R} 2_{\mathrm{FGM}}\right] / \mathrm{R} 2_{\mathrm{FGM}}=0.3[\mathrm{Fig}\right.$ $5 b])$.

These findings suggest that contrast in the neonatal brain, although ultimately dependent on a particular imaging sequence, is very different from that in the adult brain at 3.0 T. From these results, R2-based contrast may be of more interest for neonatal imaging studies that require good discrimination between GM and WM. A rigorous comparison of the contrast-to-noise ratio for imaging sequences with R1 versus R2 contrast, however, would require calculations of contrast-to-noise ratio per unit time specific to the particular sequences of interest. These calculations could be performed by using R1 and R2 values provided here.

\section{Comparison with Results at Lower Field Strengths}

A comparison of our 3.0-T MR imaging relaxation rate measurements with those obtained at lower field strengths in other studies is provided in Table 4 . Our data are consistent with the expected increase in T1 with field strength (ie, decrease in R1 with field strength), as projected from studies in adults (9-12). On the other hand, our values for T2 are similar to typical values obtained at MR imaging with field strengths of $2.4 \mathrm{~T}$ (14), $2.35 \mathrm{~T}$ 


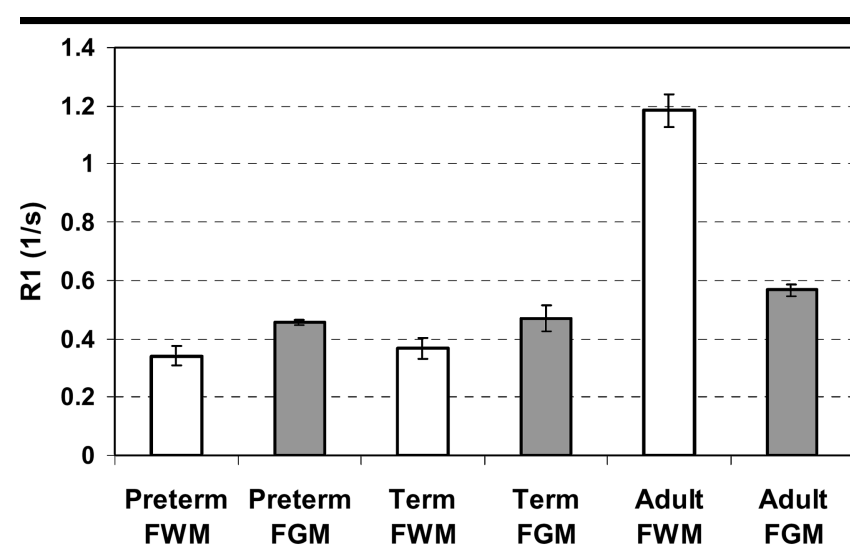

a.

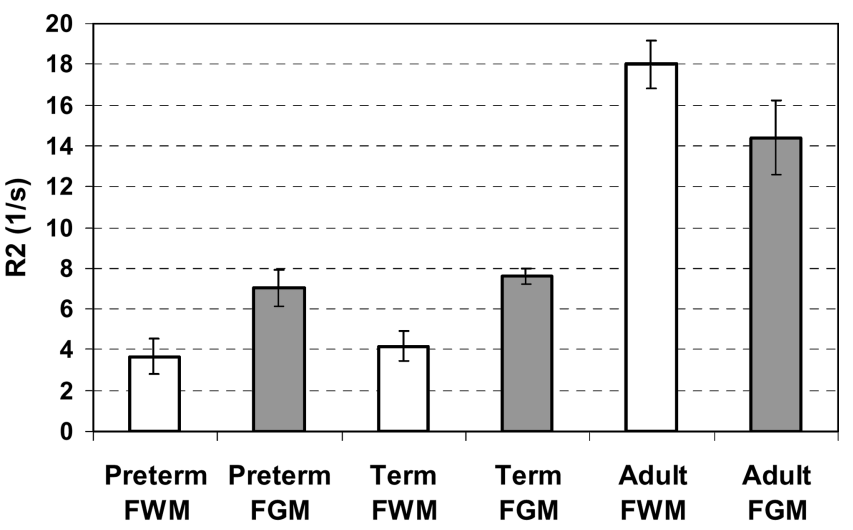

b.

Figure 5. Graphs show R1 and R2 values for frontal WM (FWM) and frontal GM (FGM) in premature infants, term infants, and healthy adults. Mean R1 and R2 values were plotted for each subset. Error bars indicate the standard deviation for each group. This figure illustrates that, for neonatal brain, R2 has better potential than does R1 for discrimination between GM and WM. In adult brain, R1 contrast often is more useful than is R2 contrast for differentiation between GM and WM. Graphs illustrate that R1 and R2 increase as the brain matures and that this increase is greater in WM than it is in GM. (a) R1 values. (Data for adults were obtained from reference 11.) (b) R2 values. (Data for adults were obtained from reference 28.) Prematurely born infants who were imaged at a term age were included in the term infant group for both $\mathbf{a}$ and $\mathbf{b}$.

(15), $1.5 \mathrm{~T}(17,18)$, and $1.0 \mathrm{~T}(16,19)$. The variation in relaxation times according to gestational age $(13,14,16,20)$ and abnormality (17) limits the interpretation of results of this comparison.

\section{Potential Limitations}

A potential limitation of performing R2 measurements by using a single spinecho acquisition, rather than a multiecho sequence (eg, Carr-Purcell-Meiboom-Gill method [39]), involves the influence of diffusion through mesoscopic magnetic field gradients on R2. It has been shown that, in multiecho acquisitions, R2 increases with the time between refocusing pulses, and this effect is known as interecho time-dependent transverse relaxation enhancement $(40,41)$. This enhancement occurs because the irreversible decay associated with diffusion has more time to evolve with longer refocusing times. For measurements of R2 that are based on separate single-echo acquisitions (as used in this study), one might expect that the influence of diffusion on R2 would increase with increasing TE and, hence, vary along the decay curve.

The amount by which R2 increases with increasing interecho time, however, has been found to be related to the concentration of ferritin in adult brain tissue $(40,41)$. In frontal WM, which has one of the lowest ferritin concentrations (ap- proximately $4.2 \mathrm{mg} / 100 \mathrm{~g}$ fresh weight [32]) in adult brain regions, a 10-fold decrease in the interecho spacing produced a decrease of $0.82 \mathrm{sec}^{-1}$ in the value of R2 at $1.5 \mathrm{~T}$ (41). In neonates, this effect should be even smaller because the concentration of brain ferritin is much lower (ranging from approximately $0.3 \mathrm{mg} / 100$ $\mathrm{g}$ fresh weight in frontal WM to $0.7 \mathrm{mg} /$ $100 \mathrm{~g}$ fresh weight in the occipital cortex [32]). Thus, this diffusion effect likely provides only a small contribution to the measured values for R2 in our study.

Multiecho sequences were not considered practical for the purpose of measuring values for interregional relaxation rates in the neonatal brain at 3.0 T. The precision of $\mathrm{R} 2$ measurements with a sequence that is based on the Carr-PurcellMeiboom-Gill method (39) relies heavily on the homogeneity of both the $B_{0}$ and $B_{1}$ fields (42). In some previous studies involving T2 measurements in the brain at $1.5 \mathrm{~T}(43,44)$, nonselective refocusing radiofrequency pulses were applied, which minimized errors in T2 measurement associated with $B_{1}$ variation. This, however, limited the acquisition to a single section. Since $B_{1}$ variation within the head increases with field strength, it is even more difficult to obtain accurate flip angles and, thus, accurate measurements of $\mathrm{R} 2$ at $3.0 \mathrm{~T}$ than it is to obtain measurements of $\mathrm{R} 2$ at $1.5 \mathrm{~T}$. In addition, the increase in the specific absorption rate with field strength creates further problems for determination of multiecho T2 measurements at $3.0 \mathrm{~T}$.

In our analysis of values of R2 relaxation rates, we assumed a single exponential decay. Results in previous reports of transverse relaxation rate measurements in adult brains have demonstrated at least two decay components, with T2 values of roughly $10-50 \mathrm{msec}$ and $70-$ 120 msec $(43,45,46)$. The shorter T2 component, which is thought to be associated with myelin water, contributes approximately $2 \%-24 \%$ of the signal intensity, depending on region of the brain $(43,45,46)$. We would expect the magnitude of this short component to be much smaller in neonatal brain tissue than in adult brain tissue, because, in the neonate, myelination occurs at a very early stage in most regions. In this study, for regions examined that have myelin levels that are closer to adult myelin levels, such as the thalamus and basal ganglia, the adult fractions of myelin water were reported to be less than $6 \%$ (43).

This study included a small cohort of neonates who were referred for examination because they were suspected of hav- 
TABLE 4

In Vivo T1 and T2 Values at Various Field Strengths in the Neonatal Brain

\begin{tabular}{|c|c|c|c|c|c|c|c|}
\hline \multirow[b]{2}{*}{ Reference } & \multirow{2}{*}{$\begin{array}{l}\text { Field } \\
\text { Strength } \\
\quad(T)\end{array}$} & \multirow{2}{*}{$\begin{array}{l}\text { No. of } \\
\text { Infants* }\end{array}$} & \multirow[b]{2}{*}{ Diagnosis } & \multicolumn{2}{|c|}{$\mathrm{ROI}$ in $\mathrm{WM}^{\dagger}$} & \multicolumn{2}{|c|}{ ROI in Thalamus } \\
\hline & & & & T1 & $\mathrm{T} 2$ & T1 & $\mathrm{T} 2$ \\
\hline Present study & 3.0 & $7 \mathrm{PP}$ & $\ldots$ & $2745 \pm 255$ & $278 \pm 69$ & $2084 \pm 199$ & $146 \pm 8$ \\
\hline Present study & 3.0 & 4 PT & $\ldots \ddagger$ & $2934 \pm 93$ & $265 \pm 56$ & $2254 \pm 11$ & $137 \pm 14$ \\
\hline Present study & 3.0 & $2 \mathrm{TT}$ & $\ldots \ddagger$ & $2556 \pm 208$ & $210 \pm 20$ & $1913 \pm 38$ & $123 \pm 9$ \\
\hline Thornton et al (14) & 2.4 & $11 \mathrm{TT}$ & Healthy & ND & $228 \pm 32$ & ND & $141 \pm 16$ \\
\hline Ferrie et al (15) & 2.35 & $7 \mathrm{PT}$ & Healthy & ND & $266 \pm 35$ & ND & $151 \pm 11$ \\
\hline Counsell et al (17) & 1.5 & 6 PT & Healthy & $1446(1332-1592)^{\S}$ & $283(223-320)^{\S}$ & $1135(1066-1253)^{\S}$ & $160(149-190)^{\S}$ \\
\hline Counsell et al (17) & 1.5 & $3 \mathrm{PT}$ & $\begin{array}{l}\text { Periventricular } \\
\text { leukomalacia }\end{array}$ & $1764(1725-1856)^{\S}$ & $369(345-595)^{\S}$ & $1250(1086-1251)^{\S}$ & $173(162-178)^{\S}$ \\
\hline Lewis et al (18) & 1.5 & $12 \mathrm{PT}$ & Not specified & $1729(1553-2415)^{\S \|}$ & $346(229-409)^{\S \|}$ & ND & ND \\
\hline Counsell et al (16) & 1.0 & 9 PP & Healthy & ND & $274 \pm 13$ & ND & $157 \pm 9$ \\
\hline Counsell et al (16) & 1.0 & 5 PT & Healthy & ND & $222 \pm 18$ & ND & $143 \pm 15$ \\
\hline Herlihy et al (19) & 1.0 & $18 \mathrm{PP}$ & Not specified & $1485 \pm 187^{\#}$ & $258 \pm 14^{\#}$ & $1129 \pm 116^{* *}$ & $165 \pm 17^{* *}$ \\
\hline \multicolumn{8}{|c|}{$\begin{array}{l}\text { * PP }=\text { preterm infants imaged at a premature age, PT }=\text { preterm infants imaged at a term age, TT }=\text { term infants imaged at a term age. } \\
\dagger \text { Unless otherwise specified, data are expressed as mean milliseconds } \pm \text { standard deviation. Values reported are for frontal WM unless otherwise } \\
\text { indicated. ND = no data. }\end{array}$} \\
\hline
\end{tabular}

ing a neurologic abnormality. Thus, the measurements presented may be valid only for infants with similar clinical findings at presentation. Infants who are suspected of having neurologic abnormalities, however, most often undergo MR imaging examinations. For that reason, the presented relaxation rate measurements provide important information for optimizing sequences used for clinical imaging at $3.0 \mathrm{~T}$ in neonates.

In conclusion, as expected for MR imaging in the neonatal brain at $3.0 \mathrm{~T}$, there is a decrease in values for the in vivo longitudinal relaxation rate, R1, compared with values reported at lower field strengths. At 3.0 T, however, the values for the transverse relaxation rate, $\mathrm{R} 2$, appear to be similar to values reported at lower field strengths (1.0-2.4 T).

Our results show a strong correlation among the in vivo interregional variations in values for the longitudinal and transverse relaxation rates, $\mathrm{R} 1$ and $\mathrm{R} 2$, respectively, for regions of the frontal $\mathrm{WM}$, frontal GM, posterior WM, posterior GM, periventricular WM, thalamus, and basal ganglia in the neonatal brain at $3.0 \mathrm{~T}$. This correlation suggests that, in the neonatal brain, the interregional variation in R1 and R2 values may largely reflect variations in the same tissue property, possibly tissue water content. This is in contrast to values for relaxation rates in adult brain tissue, where the $\mathrm{R} 2$ variation appears to be strongly influenced by tissue ferritin levels.

In addition, our results indicate that R2 contrast may be more advantageous than R1 contrast for discrimination between GM and WM regions in the neonatal brain. This is the reverse of that in the adult brain, where $\mathrm{R} 1$ contrast often is more useful than R2 contrast for differentiation between GM and WM.

Acknowledgments: The authors thank John $\mathrm{M}$. Rogers, MD, for his invaluable assistance in identifying neonatal neuroanatomy, Yves Bureau, $\mathrm{PhD}$, for sharing his statistical expertise, and the physician, nursing, and respiratory therapy staff of St Joseph's Health Care Neonatal Intensive Care Unit for their essential support.

\section{References}

1. Counsell SJ, Maalouf EF, Fletcher AM, et al. MR imaging assessment of myelination in the very preterm brain. AJNR Am J Neuroradiol 2002; 23:872-881.

2. Paus T, Collins DL, Evans AC, Leonard G, Pike B, Zijdenbos A. Maturation of white matter in the human brain: a review of magnetic resonance studies. Brain Res Bull 2001; 54:255-266.

3. Martin E, Kikinis R, Zuerrer M, et al. Developmental stages of human brain: an MR study. J Comput Assist Tomogr 1988; 12:917-922.

4. Hittmair K, Wimberger D, Rand T, et al. MR assessment of brain maturation: comparison of sequences. AJNR Am J Neuroradiol 1994; 15:425-433.

5. McArdle CB, Richardson CJ, Nicholas DA, Mirfakhraee M, Hayden CK, Amparo EG. Developmental features of the neonatal brain: MR imaging. I. Gray-white matter differentiation and myelination. Radiology 1987; 162:223-229.

6. Huppi PS, Warfield S, Kikinis R, et al. Quantitative magnetic resonance imaging of brain development in premature and mature newborns. Ann Neurol 1998; 43:224-235.

7. Toft PB, Leth H, Ring PB, Peitersen B, Lou HC, Henriksen O. Volumetric analysis of the normal infant brain and in intrauterine growth retardation. Early Hum Dev 1995; 43:15-29.

8. Bottomley PA, Foster TH, Argersinger RE, Pfeifer LM. A review of normal tissue hydrogen NMR relaxation times and relaxation mechanisms from 1-100 MHz: dependence on tissue type, NMR frequency, temperature, species, excision, and age. Med Phys 1984; 11:425-448.

9. Wansapura JP, Holland SK, Dunn RS, Ball WS, Jr. NMR relaxation times in the human brain at 3.0 tesla. J Magn Reson Imaging 1999; 9:531-538.

10. Jezzard P, Duewell S, Balaban RS. MR relaxation times in human brain: measurement at 4 T. Radiology 1996; 199:773779 .

11. Gelman N, Ewing JR, Gorell JM, Spickler EM, Solomon EG. Interregional variation of longitudinal relaxation rates in human brain at 3.0 T: relation to estimated iron and water contents. Magn Reson Med $2001 ; 45: 71-79$.

12. Vymazal J, Brooks RA, Baumgarner C, et al. The relation between brain iron and NMR relaxation times: an in vitro study. Magn Reson Med 1996; 35:56-61.

13. Suhonen-Polvi H, Maattanen H, Alanen A, et al. Examination of infant brain maturation using ultra low field MRI. Acta Paediatr Scand 1988; 77:509-515.

14. Thornton JS, Amess PN, Penrice J, Chong WK, Wyatt JS, Ordidge RJ. Cerebral tissue water spin-spin relaxation times in human neonates at 2.4 tesla: methodology and the effects of maturation. Magn Reson Imaging 1999; 17:1289-1295.

15. Ferrie JC, Barantin L, Saliba E, et al. MR assessment of the brain maturation during the perinatal period: quantitative $\mathrm{T} 2$ 
MR study in premature newborns. Magn Reson Imaging 1999; 17:1275-1288.

16. Counsell SJ, Kennea NL, Herlihy AH, et al. T2 relaxation values in the developing preterm brain. AJNR Am J Neuroradiol 2003; 24:1654-1660.

17. Counsell SJ, Herlihy AM, Robertson NJ, et al. Elevation of $\mathrm{T} 1$ and $\mathrm{T} 2$ values in the cerebral white matter in periventricular leukomalacia (abstr). In: Proceedings of the Eighth Meeting of the International Society for Magnetic Resonance in Medicine. Berkeley, Calif: International Society for Magnetic Resonance in Medicine, 2000; 1933.

18. Lewis HJ, Allsop JM, Counsell SJ, Coutts GA, Larroche S, Rutherford MA. MR quantification of the brain in premature infants at term equivalent age (abstr). In Proceedings of the Ninth Meeting of the International Society for Magnetic Resonance in Medicine. Berkeley, Calif: International Society for Magnetic Resonance in Medicine, 2001; 405.

19. Herlihy AH, Counsell SJ, Rutherford MA, Bydder GM, Hajnal JV. T1 and T2 measurements of the preterm brain (abstr). In: Proceedings of the Seventh Meeting of the International Society for Magnetic Resonance in Medicine. Berkeley, Calif: International Society for Magnetic Resonance in Medicine, 1999; 531

20. Holland BA, Haas DK, Norman D, BrantZawadzki M, Newton TH. MRI of normal brain maturation. AJNR Am J Neuroradiol 1986; 7:201-208.

21. Brix G, Schad LR, Deimling M, Lorenz WJ. Fast and precise T1 imaging using a TOMROP sequence. Magn Reson Imaging 1990; 8:351-356.

22. Bruder $\mathrm{H}$, Fischer $\mathrm{H}$, Reinfelder $\mathrm{HE}_{2}$ Schmitt F. Image reconstruction for echo planar imaging with nonequidistant kspace sampling. Magn Reson Med 1992; 23:311-323.

23. Feinberg DA, Oshio K. Phase errors in multi-shot echo planar imaging. Magn Reson Med 1994; 32:535-539.

24. Lin W, Paczynski RP, Venkatesan R, et al. Quantitative regional brain water measurement with magnetic resonance imag- ing in a focal ischemia model. Magn Reson Med 1997; 38:303-310.

25. Kamman RL, Go KG, Berendsen HJ. Proton-nuclear magnetic resonance relaxation times in brain edema. Adv Neurol 1990; 52:401-405.

26. Fatouros PP, Marmarou A. Use of magnetic resonance imaging for in vivo measurements of water content in human brain: method and normal values. J Neurosurg 1999; 90:109-115.

27. Baratti C, Barnett AS, Pierpaoli C. Comparative MR imaging study of brain maturation in kittens with $\mathrm{T} 1, \mathrm{~T} 2$, and the trace of the diffusion tensor. Radiology 1999; 210:133-142.

28. Gelman N, Gorell JM, Barker PB, et al. MR imaging of human brain at 3.0 T: preliminary report on transverse relaxation rates and relation to estimated iron content. Radiology 1999; 210:759-767.

29. Thomas LO, Boyko OB, Anthony DC, Burger PC. MR detection of brain iron. AJNR Am J Neuroradiol 1993; 14:10431048.

30. Bartzokis G, Aravagiri M, Oldendorf WH, Mintz J, Marder SR. Field dependent transverse relaxation rate increase may be a specific measure of tissue iron stores. Magn Reson Med 1993; 29:459-464.

31. Helpern JA, Ordidge RJ, Gorell JM, Deniau JC, Welch KM. Preliminary observations of transverse relaxation rates obtained at 3 tesla from the substantia nigra of adult normal human brain. NMR Biomed 1995; 8:25-27.

32. Hallgren B, Sourander P. The effect of age on the non-haemin iron in the human brain. J Neurochem 1958; 3:41-51.

33. Aoki S, Okada Y, Nishimura K, et al. Normal deposition of brain iron in childhood and adolescence: MR imaging at $1.5 \mathrm{~T}$. Radiology 1989; 172:381-385.

34. Dobbing J, Sands J. Quantitative growth and development of human brain. Arch Dis Child 1973; 48:757-767.

35. Randall LO. Chemical topography of the brain. J Biol Chem 1938; 124:481-488.

36. Takagi H, Shapiro K, Marmarou A, Wisoff $\mathrm{H}$. Microgravimetric analysis of human brain tissue: correlation with computer- ized tomography scanning. J Neurosurg 1981; 54:797-801.

37. Bell BA, Smith MA, Kean DM, et al. Brain water measured by magnetic resonance imaging: correlation with direct estimation and changes after mannitol and dexamethasone. Lancet 1987; 1:66-69.

38. Ma J, Wehrli FW. Method for imagebased measurement of the reversible and irreversible contribution to the transverse-relaxation rate. J Magn Reson B 1996; 111:61-69.

39. Meiboom S, Gill D. Modified spin-echo method for measuring nuclear relaxation times. Rev Sci Instrum 1958; 29: 688-691.

40. Ye FQ, Allen PS. Relaxation enhancement of the transverse magnetization of water protons in paramagnetic suspensions of red blood cells. Magn Reson Med 1995; 34:713-720.

41. Ye FQ, Martin WR, Allen PS. Estimation of brain iron in vivo by means of the interecho time dependence of image contrast. Magn Reson Med 1996; 36:153158

42. Poon CS, Henkelman RM. Practical T2 quantitation for clinical applications. J Magn Reson Imaging 1992; 2:541-553.

43. Whittall KP, MacKay AL, Graeb DA, Nugent RA, Li DK, Paty DW. In vivo measurement of T2 distributions and water contents in normal human brain. Magn Reson Med 1997; 37:34-43.

44. Vavasour IM, Whittall KP, MacKay AL, Li DK, Vorobeychik G, Paty DW. A comparison between magnetization transfer ratios and myelin water percentages in normals and multiple sclerosis patients. Magn Reson Med 1998; 40:763-768.

45. Papanikolaou N, Maniatis V, Pappas J, Roussakis A, Efthimiadou R, Andreou J. Biexponential T2 relaxation time analysis of the brain: correlation with magnetization transfer ratio. Invest Radiol 2002; 37: 363-367.

46. MacKay A, Whittall K, Adler J, Li D, Paty $\mathrm{D}$, Graeb D. In vivo visualization of myelin water in brain by magnetic resonance. Magn Reson Med 1994; 31: 673-677. 